\title{
Diversidad, identidad, sexualidad Reseñando un palimpsesto
}

CASTELAR, ANDRÉS FELIPE (2015) Diversidad, identidad, sexualidad (Un palimpsesto). Cali: Universidad Icesi, pp. 266.

Andrés Castelar, autor de los textos compilados en este libro, fue un juicioso y apasionado lector de la filosofía de Judith Butler, del posmodernismo y del posestructuralismo. Gracias a estos intereses en común pudimos mantener comunicación por algunos años y establecimos discusiones que, solo tras leer a cabalidad este libro, he podido decantar por completo. Por tal razón, esta publicación póstuma, surgida como un valioso homenaje de la Universidad ICESI a la memoria de uno de sus profesores e investigadores, permite entender una trayectoria intelectual y personal inspiradora para quienes creemos en la posibilidad de construir un mundo más diverso y menos violento. Además, el libro es bastante útil para nutrir investigaciones psicológicas, antropológicas, y de filosofía y teoría aplicada. Su carácter de palimpsesto se explica por la heterogeneidad cronológica y temática de los materiales compilados: artículos publicados e inéditos y reseñas de libros.

En la primera sección del libro se reproducen artículos publicados tanto en CS como en Precedente, revistas académicas en ciencias sociales y estudios jurídicos, respectivamente, de la Facultad de Derecho y Ciencias Sociales de la Universidad Icesi. Abre con el artículo La identidad como performatividad, o de cómo se llega a ser lo que no se es, donde el autor plantea varias preguntas: ¿cómo se constituye la identidad?, ¿cómo ha tratado de explicarse históricamente?, ¿qué consecuencias tiene para ciertos sujetos la exclusión de la identidad hegemónica? Para intentar responderlas, Castelar inicia explicando la aparición de las teorías que separan el sexo del género, asimilando el 
primero a lo 'natural' y el segundo a lo 'cultural'. Desde tales teorías la identidad fue explicada como continuidad necesaria, pacífica y obvia entre lo natural y lo cultural. Si bien tuvieron mucha importancia, especialmente porque ayudaron a entender que los roles de género instauraban jerarquías no naturales entre los sexos, no logran explicar las construcciones culturales del sexo, ni sus múltiples variaciones. Al final, Castelar presenta la propuesta de la filósofa estadounidense Judith Butler, para quien la identidad se construye performativamente, esto es como una puesta en acto constante: iteración repetitiva de un original inexistente. Al igual que Butler, el autor toma como ejemplo al travestido (o a la Butch, su versión lésbica) para mostrar que el rechazo y el aislamiento social crea resistencias, no directas ni violentas, sino paródicas de una norma en sí misma inestable.

En el segundo artículo, Familia y homoparentalidad: una revisión del tema, el autor argumenta que la multiplicidad de configuraciones familiares, lejos de socavar el concepto de familia, lo enriquece y lo hace más reflexivo y menos excluyente. Llama la atención el argumento de Castelar según el cual la familia, antes que un modelo rígido y naturalizado es un sistema abierto y caótico en constante reactualización (52). Ofrece ejemplos que muestran cómo el modelo hegemónico heterosexual y patriarcal de familia ha servido para discriminar no solo a las familias conformadas por personas del mismo sexo, sino a las de inmigrantes, especialmente en Europa y Norteamérica, bajo el supuesto de que la carencia de una figura paterna hace a los jóvenes hijos de inmigrantes más proclives al crimen, y que por ende el Estado necesitaría suplir el rol paterno. También destaca en este artículo la revisión del concepto de matrimonio y su diferencia respecto a la homoparentalidad, concepto que expresa las "prácticas de crianza de padres y madres, que fusiona los términos 'maternidad' y 'paternidad"' (43). En ese sentido, mientras que el matrimonio como institución es, paradójicamente, mantenido y reforzado por la aprobación del matrimonio entre parejas del mismo sexo, la homoparentalidad puede tomar lugar fuera del matrimonio y abarcar múltiples formas de paternidad, no solo la ejercida entre personas homosexuales, sino también por parte de madres solteras, familiares o cuidadores no necesariamente ligados por vínculos filiales. Castelar propone un reenfoque de las distintas corrientes psicológicas que habitualmente han servido para reforzar la univocidad de los modelos de paternidad heterosexual, y nos invita a pensar en la protección de parentescos nacidos de la homoparentalidad, especialmente la adopción de parejas homosexuales, la reproducción asistida o el alquiler de vientres.

El tercer artículo, Performatividad y lenguaje de odio: expresiones de la homosexualidad masculina en la ciudad de Cali, somete un interesante trabajo de campo (entrevistas semiestructuradas a hombres gay de la ciudad de Cali) a un lente teórico que permite estudiar el reforzamiento del discurso de odio homofóbico y misógino por parte de los propios hombres homosexuales. Mostrando que la reiteración del lenguaje ofensivo posibilita a su vez su contestación, el análisis abre horizontes para desafiar la reproducción 
endógena del discurso gay machista sin apelar a las comunes categorías 'homofobia internalizada' o 'endodiscriminación'. Por el contrario, propone tres categorías para clasificar la forma en que se repiten las ofensas en el discurso de los entrevistados: a) alegorías a metáforas como las familiares, garantes del orden social; b) reglas explícitas o implícitas sobre los significados de la masculinidad, y c) deseo/aversión, hacia el gay afeminado, rechazado pero a la vez necesario para la construcción de la masculinidad garante del círculo de socialización gay. El amanerado, pese a ser negado, llama permanentemente la atención e impulsa el deseo de observación, lo cual mostraría la permeabilidad de las estructuras imperantes de la masculinidad. En estas estructuras quebradizas se esconde, entonces, una oportunidad para la subversión simbólica que, lejos de imponer el reconocimiento a través de normas, cuestione los mecanismos performativos que reproducen los mensajes de odio.

En el cuarto artículo, El Estado hobbesiano: una mirada desde la filosofía de Judith Butler, el autor establece un paralelo entre algunos presupuestos fundamentales de la filosofía política de Thomas Hobbes y Judith Butler. Pese a la distancia histórica que separa a estos dos pensadores, Castelar logra mostrar la existencia de núcleos discursivos comunes que, aunque abordados de forma distinta, revelan preocupaciones y dilemas aún persistentes. Si bien Hobbes propuso un modelo analítico de la sociedad guiado por los parámetros metodológicos de las ciencias naturales, no dejó de lado la explicación de la constitución del sujeto político apelando, especialmente, a la razón humana, motor de los pactos sociales que originan los estados modernos, garantes de la terminación del temido estado de naturaleza. Luego, Castelar argumenta que la constitución del sujeto de Hobbes bien podría entenderse en términos performativos, es decir como resultado de la repetición citacional de discursos y acciones que, aunque en apariencia son consecuencia lógica de una naturaleza humana racional, subyugan enormemente al individuo (115). Al descubrir el mecanismo performativo que engendra al monstruo estatal garante del orden, se revela el establecimiento de formas de sujeción capaces de revigorizar la crítica y, con ello, de expandir el sustrato democrático del Estado. De esta forma, el ejercicio de Castelar consigue articular un andamiaje teórico crítico que renueva, sin anacronismos, la lectura de un pensador clásico como Hobbes.

La segunda parte del libro agrupa seis reseñas. Antes que presentar aquí una reseña de otras reseñas, prefiero explicar por qué estos seis libros llamaron la atención de Castelar. Del primero, Violence: Six Sideways Reflections del filósofo esloveno Slavok Zižek, rescata el argumento según el cual las soluciones rápidas para acabar con la violencia, por ejemplo a través de las donaciones a causas benévolas, terminan manteniendo el statu quo e incapacitándonos para pensar en las causas profundas que estructuran la 'violencia objetiva', mantenida por regímenes e instituciones. Castelar deja entrever que le interesa este libro porque complejiza la forma de reflexionar sobre la violencia, en vez de ofrecer soluciones afanadas que la perpetúen. 
El segundo libro reseñado es A History of Psychology: Original Sources and Contemporary Research de Ludy Benjamin Jr., para el autor, lejos de ser un manual de historia de la psicología, este libro acude a las fuentes primarias fundacionales de la disciplina. Pero lo interesante es que este libro presenta un estudio que no 'departamentaliza' ni aísla las distintas especialidades psicológicas, sino que las entiende como parte integrante de un desarrollo disciplinar complejo y sistemático.

De los dos libros reseñados de Agamben, el primero, The Signature of All Things: On The Method, recoge algunos cuestionamientos a los métodos investigativos. Castelar muestra que al haber sido él mismo investigador se interesó especialmente por el llamado de Agamben a mantener despierto nuestro 'estado de vigilancia arqueológica', es decir, a ver los procesos de producción de conocimiento como brechas de sentido que han sido llenadas en unos casos y olvidadas en otros, y buscar así maneras de abrir nuestros horizontes investigativos, especialmente hacia aquellos escollos rechazados por los métodos tradicionales. El segundo libro de Agamben, El tiempo que resta. Comentario a la Carta a los Romanos, también revela el enorme interés de Castelar hacia la innovación investigativa, en este caso tomando como ejemplo el estudio filológico realizado por Agamben al primer versículo de la "Carta de Pablo a los Romanos". En tan solo diez palabras ese versículo revela las transiciones entre teología y política, entre lo religioso y lo secular, que aún preocupan profundamente nuestras sociedades. Reconociendo la complejidad del libro, su proliferación de detalles y sus constantes argumentos etimológicos, Castelar logra alertar sobre la importancia de cuestionar el origen de las palabras en nuestro proceder investigativo.

El único libro de autoras colombianas reseñado es Feminismo y crítica jurídica. El análisis distributivo como alternativa crítica al legalismo liberal, escrito por Helena Alvear e Isabel Cristina Jaramillo. Lo que interesó al autor fue rescatar la conexión de los estudios jurídicos, usualmente constreñidos por la ortodoxia académica, con los enfoques feministas. La apertura hacia la interdisciplinariedad que propone el libro de las colombianas, desde escenarios específicos como la justicia transicional o las diferencias salariales entre hombres y mujeres, resulta ser un ejemplo digno a seguir para las demás ciencias sociales. De igual forma, el último libro reseñado da cuenta de la conciencia que tenía Castelar de la necesidad de cultivar la alianza entre los feminismos y los estudios sobre sexualidad. Para el autor, en Parité! Equidad de género y la crisis del universalismo francés, de Joan Wallach Scott, se ofrece un análisis histórico del caso francés desde la óptica de una autora norteamericana, lo cual permite analizar las diferencias que han caracterizado los movimientos de mujeres a lado y lado del Atlántico. En consecuencia, en este libro habría un valioso estudio de caso de estrategias utilizadas por las mujeres para materializar la paridad representativa, obtenida en Francia apenas en 1944.

La sección de artículos inéditos empieza con un trabajo a propósito de los 100 años de los 'Tres ensayos de teoría sexual': Freud y la libertad sexual. Aquí Castelar muestra 
algunos datos biográficos de Freud relevantes para entender cómo la libertad se configura en principio orientador de la sexualidad antes que la naturaleza o la tradición judeocristiana. Como lector contemporáneo de Freud, Castelar subraya varios sesgos en ese clásico trabajo, desde la total ausencia de un análisis sobre la mujer hasta el predominio de la moral y la estética burguesa europea de mediados del siglo XIX. De todos modos, el interés de Freud por reflexionar sobre la sexualidad sin la imposición de dogmas preexistentes resulta productivo para nuestro autor, puesto que transforma antiquísimas concepciones de la sexualidad al hacer de la conformación psíquica individual el motor de un proceso que no necesariamente tiene la perversión o la neurosis como único desenlace.

En el artículo Historia de la Psicología: una historia ¿acerca de qué?, Castelar sintetiza las críticas a las revisiones historiográficas de las ciencias, en particular de la psicología. Dichas críticas se suscitan por la existencia de tres presupuestos poco cuestionados que generan, a su vez, consecuencias epistémicas estructurales: a) la experimentación científica como método de validación último y definitivo de las hipótesis psicológicas; b) la idea implícita de progreso que acompaña el desarrollo de la historia científica, y que excluiría cualquier disertación psicológica previa al siglo XIX; c) la limitación del objeto de estudio en tanto que su experimentación demuestre eficacia práctica. Sin embargo, resaltando no solo el eurocentrismo en la historia de la psicología, Castelar propone una nueva historización que tenga en cuenta la permanente transformación de la psique humana, que imbuida en constantes crisis, haría de la historia de la psicología la historia de las crisis epistémicas y sociales de Occidente (219). Esta orientación haría más comprehensiva a esta disciplina, y le permitiría abandonar el actual estado de 'formación complementaria' que le ha asignado la academia psicológica.

En Los jóvenes y la constitución de la identidad sexual, Castelar parte de analizar el despliegue de la feminidad y la masculinidad en productos culturales de consumo masivo dentro de públicos juveniles, como la canción Womanizer de Britney Spears. Argumenta que la identidad sexual deviene artefacto de dominación en tanto que los jóvenes, en búsqueda de singularidad, son orientados a asumir uno de los dos polos del binario masculino/femenino. Acompasando su análisis con ejemplos de cine infantil y juvenil, Castelar explica la importancia de valorar formas alternativas de construcción de masculinidad y feminidad, y para ello considera que la teoría Queer puede ser el mejor insumo.

El artículo que cierra el libro, Los jóvenes como actores plenos en la construcción de relaciones sociales, busca un marco teórico para reflexionar sobre las interacciones, prácticas y demandas juveniles dentro del sistema de educación superior. Pese a este interés en una población concreta, el texto es sobre todo una revisión de los embates atravesados por las conceptualizaciones de las juventudes, y tras un breve panorama histórico, el autor muestra que lo que se entiende como juventud ha sido moldeado de 
acuerdo a los sistemas culturales de producción y sociales dominantes. Así, en nuestra sociedad postindustrial, la generación de una industria cultural juvenil globalizada daría cuenta de la rápida "juvenilización de la sociedad” (254), pero también de la importante capacidad de agencia e intervención que los jóvenes han desarrollado, especialmente desde Mayo del 68. Así, este texto pone en diálogo distintas voces que intentan pensar a los jóvenes como sujetos activos de las transformaciones sociales, y no como meros objetos pasivos de conocimiento.

La obra de un autor, en tanto que totalidad, solo puede juzgarse una vez terminada. Pero en el caso de Andrés, su prematura conclusión nos impide dar juicios definitivos, y más bien nos muestra su enorme capacidad para abrir campos reflexivos e investigativos. Dado que algunos trabajos quedaron en progreso, su componente exploratorio es más amplio que el conclusivo. Pero el excelente trabajo editorial que soporta este libro logra hacer justicia, a cabalidad, al homenaje que merece nuestro recordado y muy extrañado colega Andrés. Debemos agradecer a la Universidad Icesi, a sus amigas y amigos, colegas en general y al Grupo de Género de la misma Universidad, la iniciativa de ordenar sus trabajos y presentarlos para que el público pueda apreciar una totalidad sin límites fijos, abierta y profundamente inspiradora. 